\title{
Di Liscia, María Silvia y Soprano, Germán (2017). Burocracias estatales. Problemas, enfoques y estudios de caso en la Argentina (entre fines del siglo XIX y XX). Rosario: Prohistoria Ediciones y UNLPAM, 222 pp.
}

\author{
Ignacio Iván Araujo \\ Universidad Nacional de General Sarmiento, Argentina \\ ignacioaraujo.8@gmail.com
}

Cita sugerida: Araujo, I. I. (2018). [Revisión del libro Burocracias estatales. Problemas, enfoques y estudios de caso en la Argentina (entre fines del siglo XIX y XX) por M. S. Di Liscia y G. Soprano]. Anuario del Instituto de Historia Argentina, 18(2), e081. https://doi.org/10.24215/2314257Xe081

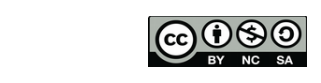




\section{Di Liscia, María Silvia y Soprano, Germán (2017). Burocracias estatales. Problemas, enfoques y estudios de caso en la Argentina (entre fines del siglo XIX y XX). Rosario: Prohistoria Ediciones y UNLPAM, 222 pp.}

Ignacio Iván Araujo

Universidad Nacional de General Sarmiento, Argentina

ignacioaraujo.8@gmail.com

En los últimos años, el campo de estudios sobre el Estado ha tenido un notable dinamismo. Problemas como la conformación de agencias y ministerios, las trayectorias de diversos funcionarios y la implementación de políticas públicas han merecido investigaciones relevantes. Asimismo, el impacto de las redes internacionales en que abrevaron las políticas públicas o las tensiones y límites que se generaron en la administración permitieron esclarecer los fenómenos que marcaron los procesos de construcción de la estatidad en los siglos XIX y XX. En particular, la obra compilada por María Di Liscia y Germán Soprano busca profundizar en los rostros humanos del Estado, como bien destacan los autores en la introducción. El encuentro de estos dos especialistas, que desde la historia y la antropología contribuyen a enriquecer e indagar aristas que recorren no solo la historia social y política, sino también la instrumentalidad teórica de la antropología social, la ciencia política o la sociología para comprender los fenómenos estatales. La propuesta reúne varios ensayos acerca de la administración pública, tanto a nivel regional como nacional, que toman modelos que han sido interpelados o reproducidos en diferentes contextos históricos. Esta cuestión permite explorar, en el largo plazo las múltiples y diversas acciones que personificaron las burocracias estatales.

El libro comienza con una introducción en donde los compiladores hacen un extenso recorrido histórico por las maneras en que fueron conceptualizadas las burocracias (no de forma lineal) a lo largo de los años y de las épocas desde la teoría social. Los autores solventan y enfatizan la cuestión epistémica tomada por cientistas sociales, tanto de los clásicos encarnados en el sociólogo Max Weber como en las reflexiones más contemporáneas suscitadas por Theda Skocpol, Antrony Guiddens o Ralph Miliband. Asimismo, ofrecen una reflexión en un pequeño apartado dedicado a la historia de la administración pública, más precisamente a los estudios comparados de los procesos que condujeron a su formación. Los compiladores concluyen realizando un esbozo acerca de la historiografía argentina "preocupada" por las burocracias, colocándolas como "una cenicienta, sin baile ni príncipe" (pág. 27) que registra escasos aportes en los estudios nacionales, si bien en los últimos años, se están realizando aportes en este aspecto. De este modo, abren una serie de preguntas que intentan responder en los siete trabajos que componen el libro en vista de realizar diferentes aportes.

El primer trabajo, de María Di Liscia, se sustenta en una exhaustiva investigación cuantitativa y cualitativa, tomando como caso de estudio la Dirección General de Inmigración y las conexiones establecidas con la eugenesia aplicada del Departamento Nacional de Higiene a principios del siglo XX. Enmarcada en el contexto de inmigración masiva en Argentina, la autora observa la legislación y la aplicación de criterios sanitarios que generaron una resistencia por parte de un gran grupo de inmigrantes, ya sea evadiendo la ley a partir de falsificaciones que demostraban la debilidad de las administraciones públicas, o apelando a las redes que iban estableciendo los sujetos calificados como "indeseables" con las personas ya establecidas en el país. Es interesante destacar las fuentes documentales utilizadas, en especial los expedientes administrativos que iluminan la experiencia de los funcionarios en cuanto a la aplicación de las leyes destinada a regular el ingreso de inmigrantes, colocando en el centro de su pesquisa la interpretación de que fueron objeto, 
así como la debilidad y la ausencia de criterios uniformes en la administración estatal. Las tensiones que provocó la aplicación de la legislación estatal también se dilucidan en el escrito de Virginia Persello en el cual documenta las pugnas internas llevadas a cabo entre especialistas formados en las ciencias económicas y los actores de organismos privados en la Comisión Nacional de Control de Cambios, constituida en la década del 30'. El período entreguerras se destaca por la crisis del modelo liberal y la emergencia de políticas económicas alternativas en una coyuntura internacional convulsionada, en particular, las ideas que defendían una economía dirigida buscando regular el control de divisas en el país. Dicha medida fiscal significó una novedad en sí misma en el nuevo rol interventor que asume el Estado en esta coyuntura, y en particular la emergencia de organismos administrativos que definieron las herramientas para poder mediar esta tarea.

Los estudios de Stella Cornelis y María José Billorou suman a la compilación un aporte interesante al tomar ejemplos que variando la escala de análisis, recuperan la especificidad de la administración estatal en el Territorio Nacional de La Pampa. La primera autora ahonda en la administración general de distintas agencias estatales, en un extenso período que abarca desde fines del siglo XIX desde su establecimiento hasta la mitad del XX, cuando se sanciona la provincialización del territorio. Cornelis observa los cambios y continuidades a lo largo de esos años, subrayando que la década del 30', se produjo un considerable aumento de personal tanto técnico como administrativo pero que encuentra factores estructurales del mismo entramado territorial que se ve socavado por la baja tasa de profesionalización y el constante problema relacionado a la escasez de presupuesto, común a los Territorios Nacionales en la primera mitad del siglo XX. En tanto, el segundo trabajo muestra el desafío que presentó la educación pública en el caso territoriano, examinando las tensiones que existieron entre las maestras como agentes culturales potentes y los inspectores escolares como supervisores y sostén profesional del poder central en la sociedad local. Otro aporte relevante que realiza Billorou es la adopción de la perspectiva de género, para comprender cómo las relaciones de los actores se encontraron atravesadas por la forma y el ejercicio de la masculinidad, y que, del mismo modo, ilumina la circulación de información administrativa en los distintos distritos que conforman el aparato educativo provincial.

Carolina Biernat y Karina Ramacciotti por un lado, y Osvaldo Graciano por otro, puntualizan en la especialización de distintas áreas de la administración estatal, teniendo en cuenta las discusiones y la circulación de saberes entre la producción de conocimientos científicos y el involucramiento de académicos universitarios que formaron parte e informaron diversas agencias públicas. Biernat y Ramacciotti analizan la conformación de una burocracia moderna en el área de salud, proceso que tuvo como hito central la conformación de la Secretaría de Salud Pública en 1947, que logró la especialización en materia sanitaria de gran cantidad de profesionales, y las transformaciones que se produjeron durante el gobierno de Frondizi, con la constitución de la Escuela de Salud Pública erigida por la Universidad de Buenos Aires. De esta forma, ponen el foco en el proceso de profesionalización donde se fueron imbricando agencias estatales y espacios académicos. Graciano, en cambio, se detiene en las investigaciones y el avance científico de una rama de la agronomía: la genética. El autor expone, a partir de un caso poco conocido, cómo a mediados de la década del 20' la creación del Instituto Fitotécnico logró atraer el interés e informar las políticas del Ministerio de Agricultura. Estos trabajos al incorporar las formas en que el saber universitario se conjugó con las administraciones y agencias públicas, iluminan un rasgo relevante de la constitución de burocracias estatales, sin descuidar en sus exploraciones que, en ocasiones, formaron parte de procesos internacionales, al demostrar como influyeron las grandes investigaciones promovidas tanto por Europa como Estados Unidos.

Por último, la obra culmina con el aporte del segundo compilador de esta obra, Germán Soprano, quién analiza las lógicas y prácticas castrenses en el contexto de la transición democrática de los años 80 , y en particular, las promociones y ascensos de generales de brigada, de división y tenientes generales. La investigación de los generalatos durante un periodo de alta conflictividad puertas adentro del ejército, evidencian las similitudes que hay entre este cuerpo del Estado y otras administraciones estatales. El clientelismo, las negociaciones, la solidaridad, entre otras, son algunas de las acciones que obedecieron 
tanto a cuestiones ideológicas como políticas, y que se encuentran sumergidas en el espacio castrense. Por último, es sumamente provechosa e interesante la utilización de entrevistas recogidas por el autor que dan cuenta de las experiencias en el seno de la burocracia militar que tuvo que redefinir su papel, en un período terminantemente belicoso tras el fin de la dictadura militar.

En suma, este es un libro se propone repensar y reconceptualizar a las burocracias, las agencias y las administraciones estatales que se han conformado a lo largo del siglo XX. Ese "gris indefinido", que representan las burocracias, como lo remarcan los autores (pág. 38) es el que hilvanan los capítulos del libro, logrando echar luz a diversos procesos a partir de diferentes perspectivas metodológicas, multidisciplinares y en escalas diferentes, sin perder de vista a los actores estatales. El mérito de la obra consiste, justamente, en ofrecer a partir de casos puntuales, cuáles fueron esas prácticas, experiencias y saberes que se pusieron en juego a la hora de comprender la conformación, profesionalización y reclutamiento de las burocracias en nuestro país. Por eso, los trabajos compilados permiten reflexionar sobre las tensiones y la porosidad de los espacios estatales -como por ejemplo con los ámbitos universitarios-, y contribuyen, al fin y al cabo, el desafío de desandar una gran cantidad de preguntas y problemas que arrojan luz al fecundo campo de los estudios sobre el Estado. 